\title{
CORRECTION
}

\section{Correction to: Pythagorean fuzzy AHP based risk assessment methodology for hazardous material transportation: an application in Istanbul}

\author{
Ertugrul Ayyildiz $^{1,2} \cdot$ Alev Taskin Gumus $^{1}$
}

Published online: 8 February 2022

๑) Springer-Verlag GmbH Germany, part of Springer Nature 2022

Correction to: Environmental Science and Pollution Research (2021) 28:35798-35810 https://doi.org/10.1007/s11356-021-13223-y

The corrected Figure 3 is presented in this paper.

Fig. 3 The steps of PF-AHP methodology

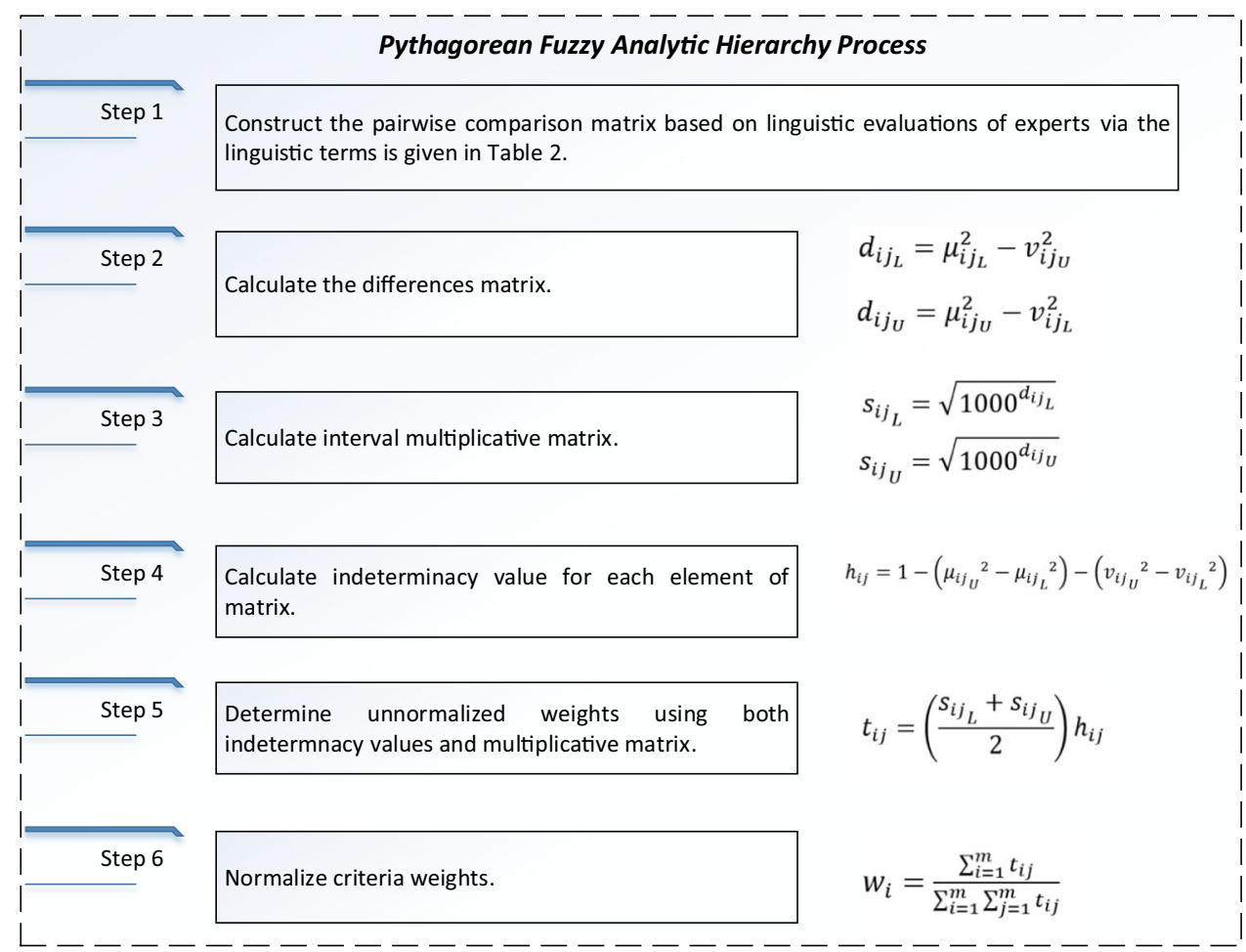

The original article can be found online at https://doi.org/10.1007/ s11356-021-13223-y.
Publisher's note Springer Nature remains neutral with regard to jurisdictional claims in published maps and institutional affiliations.

Ertugrul Ayyildiz

eayildiz@yildiz.edu.tr

1 Department of Industrial Engineering, Yıldiz Technical

University, Yıldız Campus, 34349 İstanbul, Turkey

2 Department of Industrial Engineering, Karadeniz Technical,

University, Merkez Campus, 06180 Trabzon, Turkey 